\title{
99mTc-GSA Scintigraphy with SPECT for Assessment of Hepatic Function and Functional Volume During Liver Regeneration in a Rat Model of Partial Hepatectomy
}

\author{
Wilmar de Graaf ${ }^{1}$, Reeta L. Veteläinen ${ }^{1}$, Kora de Bruin ${ }^{2}$, Arlène K. van Vliet $^{1}$, Thomas M. van Gulik ${ }^{1}$, and \\ Roelof J. Bennink ${ }^{2}$ \\ ${ }^{1}$ Department of Surgery (Surgical Laboratory), Academic Medical Center, Amsterdam, The Netherlands; and ${ }^{2}$ Department of Nuclear \\ Medicine, Academic Medical Center, Amsterdam, The Netherlands
}

Small-animal models are crucial to gain insights in the complex recovery mechanisms of liver function during liver regeneration. $99 \mathrm{~m} T c-M e b r o f e n i n$ hepatobiliary scintigraphy (HBS) has been introduced for noninvasive assessment of liver function in the clinical setting as well as in experimental research. However, HBS is restricted to planar modalities in small animals because hepatic kinetics are generally too fast for SPECT acquisition. ${ }^{99 m T c-}$ DTPA-galactosyl serum albumin (where DTPA is diethylenetriaminepentaacetic acid) ( ${ }^{99 m}$ Tc-GSA) scintigraphy is an alternative, receptor-mediated, noninvasive liver function test. After hepatic uptake, ${ }^{99 m T c-G S A ~ r e m a i n s ~ t r a p p e d ~ i n ~ t h e ~ l i v e r, ~ w h i c h ~ r e a d i l y ~ e n-~}$ ables additional SPECT for the assessment of both liver function and liver functional volume within one test. In this study we evaluated the use of ${ }^{99 m}$ Tc-GSA scintigraphy combined with SPECT for the assessment of liver function and liver functional volume in normal and regenerating rat livers. Methods: The reproducibility of $99 \mathrm{mTc}$-GSA scintigraphy and SPECT was investigated by repeated measurements within the same rat. For the assessment in a regenerating liver, ${ }^{99 m}$ Tc-GSA scintigraphy with SPECT was performed on $1,3,5$, and $7 \mathrm{~d}$ ( $n=6$ rats per time point) after $70 \%$ partial hepatectomy $(\mathrm{PH})$. Results: The correlation between repeated 99mTc-GSA measurements was strong $(r=0.75, P=$ $0.019)$. In normal rat livers, there was a strong, significant correlation between liver functional volume and conventional liver volume $(r=0.93$; $<0.0001)$. The correlation between ${ }^{99 m T c-G S A}$ uptake and liver volume was moderate $(r=0.62, P=0.043)$. Dur-

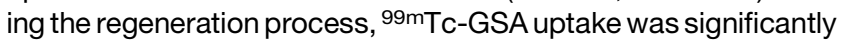
lower compared with both liver volume $(P<0.001)$ and liver functional volume $(P<0.001)$, when expressed as a percentage of baseline levels. There was a strong correlation between liver functional volume and conventional liver volume in the regenerating liver $(r=0.92, P<0.0001)$. Conclusion: ${ }^{99 m T c-G S A ~ s c i n t i g r a p h y ~}$ combined with SPECT is a feasible, noninvasive method to assess hepatic functional volume in normal rat liver as well as in the regenerating rat liver. However, the hepatic ${ }^{99 m}$ Tc-GSA uptake

Received Jun. 22, 2007; revision accepted Sep. 21, 2007.

For correspondence contact: Thomas M. van Gulik, MD, PhD, Department of Surgery, Academic Medical Center, Meibergdreef 9, IWO-1, 1105 AZ Amsterdam, The Netherlands.

E-mail: t.m.vangulik@amc.uva.nl

COPYRIGHT @ 2008 by the Society of Nuclear Medicine, Inc. as a liver function test seems to underestimate hepatic regeneration in comparison to liver volume.

Key Words: liver function; liver functional volume; liver regeneration; ${ }^{99 m T C-G S A ~ s c i n t i g r a p h y ~}$

J Nucl Med 2008; 49:122-128

DOI: 10.2967/jnumed.107.044255

$\mathbf{P}$ artial liver resection is the most effective treatment for primary and secondary liver malignancies (1). To ensure safe postoperative recovery, sufficient remnant liver volume and function are crucial as posthepatectomy liver failure still has high mortality. When sufficient remnant liver is present, the liver has the unique ability to regenerate to its original size. Several conditions are known to influence liver regeneration, including the extent of resection, the presence of underlying parenchymal liver disease (2), diabetes, and the age of the patient (3). Impaired liver regeneration can cause serious clinical problems, such as delayed recovery of postoperative liver function and increased risk of postoperative liver failure.

Despite extensive research, the mechanisms underlying the complex recovery of hepatocellular volume and function that occur during liver regeneration are not completely understood. As liver regeneration is difficult to study in humans, a standardized rat model of $70 \%$ partial hepatectomy (PH) is commonly used. In this model, liver regeneration is generally assessed by measuring the increase of liver volume and the mitotic index $(2,4)$. However, as demonstrated in clinical studies, liver volume does not always represent liver function, indicating the importance of additional functional assessment of the liver during liver regeneration (5-7). Development of new therapeutic strategies to enhance liver regeneration has further increased the importance of additional functional assessment in the rat model. To facilitate and reduce the number of animals needed for research in the field of liver surgery, noninvasive 
assessment of liver function has been introduced using ${ }^{99 m}$ Tc-mebrofenin hepatobiliary scintigraphy (HBS) in both acute and chronic experimental animal models (8-11). However, scintigraphic imaging acquisition is restricted to planar modalities because hepatic kinetics of ${ }^{99 \mathrm{~m}} \mathrm{Tc}$-mebrofenin in small animals are too fast for (pinhole) SPECT acquisition. An alternative radiopharmaceutical for liver function scintigraphy is ${ }^{99 m}$ Tc-DTPA-galactosyl serum albumin (where DTPA is diethylenetriaminepentaacetic acid) ( ${ }^{99 m}$ Tc-GSA) (12). Although it is not registered for clinical use outside Japan, ${ }^{99 \mathrm{~m}} \mathrm{Tc}-\mathrm{GSA}$ is available for preclinical investigation elsewhere. ${ }^{99 \mathrm{~m} T c-G S A}$ scintigraphy is based on the hepatic pharmacokinetics of asialoglycoproteins (ASGP). ASGP is a serum galactose-terminated glycoprotein, which binds to the ASGP receptor and is subsequently internalized via receptor mediated endocytosis. The ASGP receptor is expressed in large quantities on the hepatocyte sinusoidal surface (13) and its expression reflects the severity of chronic liver disease, such as cirrhosis (14-16). ${ }^{99 \mathrm{~m} T c-G S A}$ was developed as a synthetic asialoglyoprotein to visualize and quantify its hepatic binding to the ASGP receptor. After intravenous injection and hepatic uptake, ${ }^{99 \mathrm{~m} T c-G S A}$ remains trapped in the liver for at least $30 \mathrm{~min}$ (17). This would potentially enable pinhole SPECT acquisition in small laboratory animals for the assessment of both liver function and liver functional volume.

The aim of this study was to evaluate the use of ${ }^{99 \mathrm{~m}} \mathrm{Tc}-$ GSA scintigraphy as a liver function imaging technique in combination with ${ }^{99 \mathrm{~m} T c-G S A}$ SPECT for additional assessment of liver functional volume in a normal and regenerating rat liver.

\section{MATERIALS AND METHODS}

\section{Animals and Reagents}

Male Wistar rats (Harlan) were acclimatized for $1 \mathrm{wk}$ under standardized laboratory conditions in a temperature-controlled room with a $12 \mathrm{~h}$-light/12-h dark cycle on standard rat chow and water ad libitum. ${ }^{99 m}$ Tc-GSA was kindly provided by Nihon Mediphysics. This study was approved by the Animal Ethics and Welfare Committee of the Academic Medical Center, University of Amsterdam, Amsterdam, The Netherlands.

\section{Camera Design}

For imaging of ${ }^{99 \mathrm{~m}} \mathrm{Tc}-\mathrm{GSA}$ uptake in the rat liver, a $\gamma$-camera (ARC 3000; Philips) available in a dedicated animal care facility was equipped with a pinhole collimator fitted with a 3-mm tungsten insert. The pinhole collimator was facing up. On the detector, a mechanical support was mounted in which the animal is fixed in an acrylic cylinder positioned exactly above the pinhole collimator. The mechanical support was designed to place the midline of the cylinder exactly in the middle of the pinhole. The position of the animal is adjustable in the axial dimension. Furthermore, the distance from the cylinder to the pinhole aperture is adjustable. Therefore, this gantry permits optimal pinhole scintigraphy of anterior projections of rats, standardizing magnification and orientation (18). The $\gamma$-camera is interfaced to a Hermes acquisition station (Nuclear Diagnostics).

\section{Scintigraphy and Interpretation}

The animals were sedated with a mixture of $\mathrm{O}_{2} / \mathrm{N}_{2} \mathrm{O}(1: 1 \mathrm{v} / \mathrm{v}, 2$ $\mathrm{L} / \mathrm{min}$ ) and isoflurane (2\%-3\% Florene; Abbott Laboratories Ltd.). Once anesthetized, a bolus of $40 \mathrm{MBq}{ }^{99 \mathrm{~m}} \mathrm{Tc}-\mathrm{GSA}$ in 0.3 $\mathrm{mL}$ saline was injected in the tail vein. The animals were scanned on injection of the radiopharmaceutical in anterior position with the liver and the mediastinum in the field of view (FOV). For dynamic ${ }^{99 \mathrm{~m}} \mathrm{Tc}-\mathrm{GSA}$ scintigraphy, images were obtained for 30 min (10 min at $5 \mathrm{~s}$ per frame and $20 \mathrm{~min}$ at $60 \mathrm{~s}$ per frame) at the $140-\mathrm{keV}{ }^{99 \mathrm{~m}}$ Tc peak with a $20 \%$ window in a $128 \times 128$ matrix. Data were processed on a Hermes workstation (Nuclear Diagnostics). In clinical studies, liver function, measured by ${ }^{99 \mathrm{~m} T c-G S A}$ scintigraphy, is expressed by many different, sometimes complex, parameters. The most commonly used parameters in planar, dynamic ${ }^{99 m}$ Tc-GSA scintigraphy are the hepatic uptake ratio of 99mTc-GSA (LHL15) and the blood clearance ratio (HH15) $(12,19)$ We used the ${ }^{99 m}$ Tc-GSA liver uptake based on a technique described by Ekman et al. (20). The algorithm was adapted for rat scintigraphy based on the faster hepatic uptake of ${ }^{99 \mathrm{~m}} \mathrm{Tc}-\mathrm{GSA}$ in rats (21). Regions of interest (ROIs) were drawn around the liver, heart, and large vessels within the mediastinum (serving as blood pool) and around the total FOV (indicative of total activity). The liver ROI was drawn automatically on a threshold-based algorithm using $20 \%$ of the maximum liver value on a summed image of the first $2.5 \mathrm{~min}$ of the acquisition as cutoff. Three different timeactivity curves were generated based on the liver, blood pool, and total FOV. Liver uptake was calculated in $\% / \mathrm{min}$, based on these 3 parameters. Calculations of hepatic ${ }^{99 \mathrm{~m}} \mathrm{Tc}-\mathrm{GSA}$ uptake were performed using scanned radioactivity values acquired between 60 and $180 \mathrm{~s}$ after injection to make sure that calculations were made during a phase of homogeneous distribution of the agent in the blood pool.

SPECT acquisition was performed $30 \mathrm{~min}$ after intravenous injection of ${ }^{99 \mathrm{~m}} \mathrm{Tc}-\mathrm{GSA}$. Fifty projections $(128 \times 128$ matrix $)$ were made in a $360^{\circ}$ orbit. The acquisition time per projection was $25 \mathrm{~s}$. SPECT reconstruction was performed with a Hermes application program adapted to pinhole SPECT, using filtered backprojection (Fig. 1) (18). A Butterworth postreconstruction filter (order 5; 0.8 cycle/cm) was applied. After completion of the reconstruction, the outline extraction method with a threshold of $40 \%$ of the maximal voxel count value was applied for determination of the liver functional volume (22).

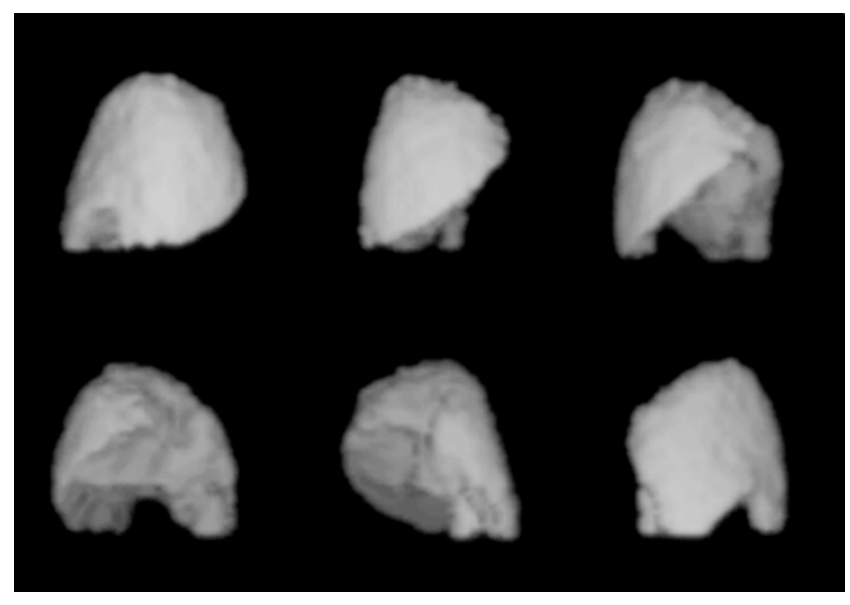

FIGURE 1. 99mTc-GSA SPECT reconstruction. 


\section{Reproducibility}

Nine rats were anesthetized by inhalation with a mixture of $\mathrm{O}_{2} /$ $\mathrm{N}_{2} \mathrm{O}(1: 1 \mathrm{v} / \mathrm{v}, 2 \mathrm{~L} / \mathrm{min})$ and isoflurane $2 \%-3 \%$ and scanned on 2 separate days with a $2 \mathrm{~d}$ time interval, to assess the reproducibility of scintigraphic liver function testing and intrasubject variation. Subsequently, a SPECT acquisition of 25 min was made. After the final scintigraphy, livers were removed and the liver volume and weight were determined. Conventional liver volume was calculated as previously described (23).

\section{Surgical Procedure}

Rats (250-300 g) were anesthetized by a mixture of $\mathrm{O}_{2} / \mathrm{N}_{2} \mathrm{O}$ $(1: 1 \mathrm{v} / \mathrm{v}, 2 \mathrm{~L} / \mathrm{min})$ and isoflurane $2 \%-3 \%$ and adequate analgesia was achieved by administration of buprenorphine (Temgesic [Schering-Plough], subcutaneous; $0.33 \mathrm{mg} / \mathrm{kg}$ ). After midline laparotomy, the liver was mobilized. Partial (70\%) hepatectomy was performed by resecting median and left lateral lobes. The abdomen was closed in 2 layers using a 4/0 Vicryl suture (Ethicon), and the animals were allowed to wake up.

\section{Experimental Groups}

Two groups of rats in different weight categories, group A; 250-300 $\mathrm{g}(n=6)$ and group B; 300-350 $\mathrm{g}(n=6)$, were used to compare liver volume and liver functional volume measured by ${ }^{99 \mathrm{~m} T c-G S A ~ S P E C T}$. For the assessment of liver regeneration, 30 rats were randomized into 5 experimental groups. In a control group $(n=6),{ }^{99 m}$ Tc-GSA scintigraphy with SPECT was performed to calculate normal (baseline) ${ }^{99 m} \mathrm{Tc}-\mathrm{GSA}$ uptake and liver functional volume. Subsequently, rats were sacrificed to determine baseline liver weight and liver volume. For the assessment of liver regeneration, rats were anaesthetized $1(n=6), 3$ $(n=6), 5(n=6)$ and $7(n=6)$ days after $70 \% \mathrm{PH}$ and ${ }^{99 \mathrm{~m}} \mathrm{Tc}-$ GSA scintigraphy with SPECT was performed to calculate ${ }^{99 \mathrm{~m}} \mathrm{Tc}-$ GSA uptake and liver functional volume. After sacrifice, liver weight and conventional liver volume were determined.

\section{Statistical Analysis}

Commercial computer packages were used for the analysis of the data (GraphPad Prism 4; SPSS 12.01 for Windows). Continuous data was compared by independent sample $t$ test and expressed as mean $\pm \mathrm{SE}$ of the mean (SEM). A correlation between variables was tested using the Pearson correlation coefficient $r$. The scintigraphy calculations were further analyzed to the method of Bland-Altman, which is a supplementary method to compare 2 different methods when the true value is unknown. The data was plotted as scatter plot of the mean values versus the difference of both calculations. Differences between postoperative ${ }^{99 \mathrm{~m}} \mathrm{Tc}-\mathrm{GSA}$ uptake, liver functional volume and conventional volume measurements were evaluated with the Wilcoxon signed rank test and a nonparametric repeated measurement ANOVA test. All statistical tests were 2-tailed and differences were considered significant at a $P$ value $<0.05$.

\section{RESULTS}

\section{Reproducibility of ${ }^{99 m}$ Tc-GSA Calculations}

The hepatic uptake of ${ }^{99 \mathrm{~m}} \mathrm{Tc}-\mathrm{GSA}$ was homogenous in all liver lobes (Fig. 2). The uptake rate remained constant after $10 \mathrm{~min}$ of imaging. The ${ }^{99 \mathrm{~m}} \mathrm{Tc}-\mathrm{GSA}$ uptake was measured twice within the same animal, with a time interval of $2 \mathrm{~d}$. No remaining radioactivity was detected in the second measurement before reinjection. There was a strong corre- lation between the 2 measurements (Fig. 3A; Pearson $r=$ 0.75, $P=0.019$ ). Bland-Altman analysis (Fig. 3B) revealed only a small bias between the 2 observers (mean bias of $-1.49 \% / \mathrm{min}[4.5 \%]$ ) with the $95 \%$ limit of agreement between $-10.22 \% / \mathrm{min}$ and $7.24 \% / \mathrm{min}$.

\section{Comparison Between Functional Volume, ${ }^{99 m}$ Tc-GSA Uptake, and Liver Volume in Normal Livers}

Comparison between conventional liver volume and liver functional volume measured by ${ }^{99 \mathrm{~m}} \mathrm{Tc}-\mathrm{GSA}$ SPECT was performed in 2 groups $(n=6)$ of rats in different weight categories (group A; 250-300 g; and group B, 300-350 g). One rat was excluded because of subcutaneous injection of $99 \mathrm{~m}$ Tc-GSA. Conventional liver volume and liver functional volume in group A was $12.38 \pm 0.32 \mathrm{~mL}$ and $12.33 \pm 0.25$ $\mathrm{mL}$, respectively, and in group B was $18.23 \pm 0.45 \mathrm{~mL}$ and $17.33 \pm 0.68 \mathrm{~mL}$, respectively. Conventional liver volume and liver functional volume were significantly different between the 2 groups $(P=0.0043, P=0.002$; MannWhitney test). ${ }^{99 \mathrm{~m}} \mathrm{Tc}-\mathrm{GSA}$ uptake in group A was $25.40 \%$ $\pm 0.87 \% / \mathrm{min}$ and in group B was $33.10 \% \pm 2.07 \% / \mathrm{min}$. 99m Tc-GSA uptake was not significantly different between the groups $(P=0.052)$. There was no significant difference between liver volume and functional volume within both groups $(P=0.079$ and $P=0.18)$. The correlation between conventional liver volume and liver functional volume was strong and significant (Pearson $r=0.971, P<0.0001$; Fig. 4A). The correlation between GSA uptake and conventional liver volume was moderate (Pearson $r=0.62, P=0.043$; Fig. 4B).

\section{Liver Volume During Liver Regeneration}

Mean conventional liver volume was decreased $1 \mathrm{~d}$ after $70 \% \mathrm{PH}(6.77 \pm 0.12 \mathrm{~mL})$ compared with baseline $(12.38$ $\pm 0.32 \mathrm{~mL}$ ), after which it increased from $9.08 \pm 0.77 \mathrm{~mL}$ at day 3 to normal liver volume at day $5(12.15 \pm 0.45 \mathrm{~mL})$ and day 7 (11.76 $\pm 0.50 \mathrm{~mL}$, Fig. 5A).

99mTc-GSA SPECT was used to calculate functional liver volume. The mean baseline functional volume was $12.14 \pm$ $0.20 \mathrm{~mL}$. One day after $\mathrm{PH}$, functional volume was reduced to $8.07 \pm 0.27 \mathrm{~mL}$. Similar to conventional liver volume, the functional volume increased by day $3(9.68 \pm 0.92 \mathrm{~mL})$ to normal liver functional volume on day $5(11.82 \pm 0.39$ $\mathrm{mL})$ and day $7(11.80 \pm 0.37 \mathrm{~mL})$ (Fig. $5 \mathrm{~A})$.

There was a significant difference at day 1 between conventional liver volume and liver functional volume assessed by ${ }^{99 \mathrm{~m} T c-G S A}$ SPECT $(6.77 \pm 0.12 \mathrm{~mL}$ and $8.07 \pm 0.27 \mathrm{~mL}$, respectively; $P=0.048$, Wilcoxon signed rank test). There were no significant differences between the volumes assessed by both methods at baseline, 3,5 , and $7 \mathrm{~d}$ after $70 \% \mathrm{PH},(P=0.14, P=0.71, P=0.69$ and $P=$ 0.92 , respectively). The correlation between the 2 volumes in the regenerating liver was strong and significant (Pearson $r=0.924, P<0.0001$; Fig. 5B). 


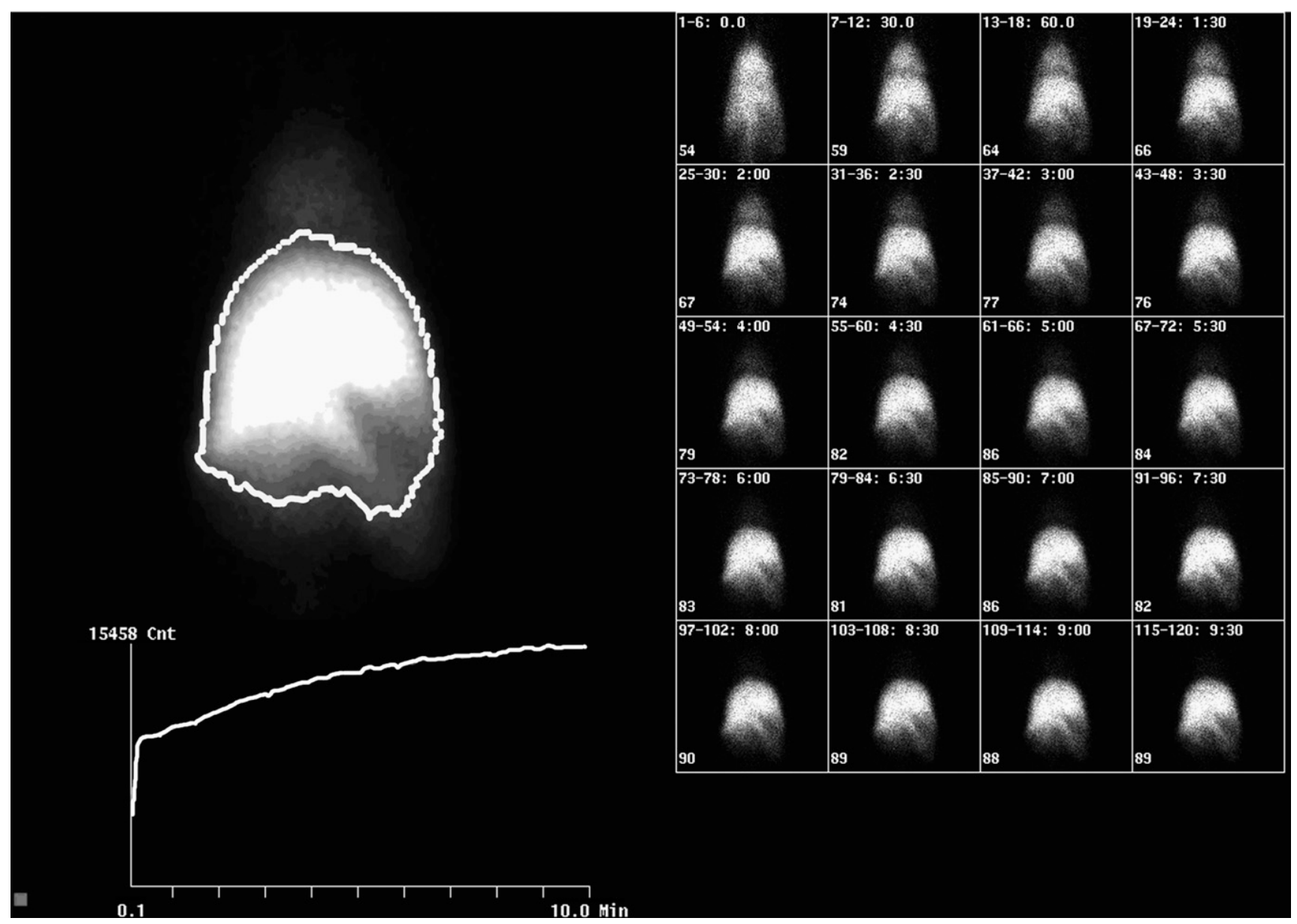

FIGURE 2. Dynamic scintigraphy in control rat after intravenous administration of $40 \mathrm{MBq}{ }^{99 m}$ Tc-GSA in tail vein. (Right panel) Reframed images of dynamic acquisition. There is homogeneous liver uptake from blood-pool activity within 5 min. There is no excretion of tracer within bile to the intestinal tract. (Upper left panel) Summed image with liver in the ROI (white line). (Lower left panel) Time-activity curve of liver ROI, with accumulation to a plateau phase at 10 min after injection.

\section{9mTc-GSA Uptake During Liver Regeneration}

The mean baseline level of ${ }^{99 m}$ Tc-GSA uptake in a normal liver was $27.08 \% \pm 1.82 \% / \mathrm{min}$. One day after $70 \%$ $\mathrm{PH}$, the ${ }^{99 \mathrm{~m}} \mathrm{Tc}-\mathrm{GSA}$ uptake $(8.01 \% \pm 0.62 \% / \mathrm{min})$ significantly decreased compared with baseline. At 3, 5, and $7 \mathrm{~d}$ after resection, ${ }^{99 \mathrm{~m} T c-G S A}$ uptake increased again to $10.34 \% \pm 0.46 \% / \mathrm{min}, 13.53 \% \pm 1.20 \% / \mathrm{min}$, and $21.71 \% \pm 1.94 \% / \mathrm{min}$, respectively (Fig. 6).
To investigate if the decrease in uptake of ${ }^{99 \mathrm{~m}} \mathrm{Tc}-\mathrm{GSA}$ was mainly due to the decrease in liver weight after $70 \%$ $\mathrm{PH}$, the ${ }^{99 \mathrm{~m}}$ Tc-GSA uptake was divided by total liver (wet) weight. The mean baseline level of ${ }^{99 \mathrm{~m} T c-G S A}$ uptake in a normal liver was $2.44 \% \pm 0.07 \% / \mathrm{min}$ per gram liver. One day after $70 \% \mathrm{PH}$, the ${ }^{99 \mathrm{~m}} \mathrm{Tc}-\mathrm{GSA}$ uptake per gram liver decreased significantly to $1.51 \% \pm 0.08 \% / \mathrm{min} / \mathrm{g}$ (vs. baseline, $P<0.008$; Mann-Whitney test) (Table 1). At 3

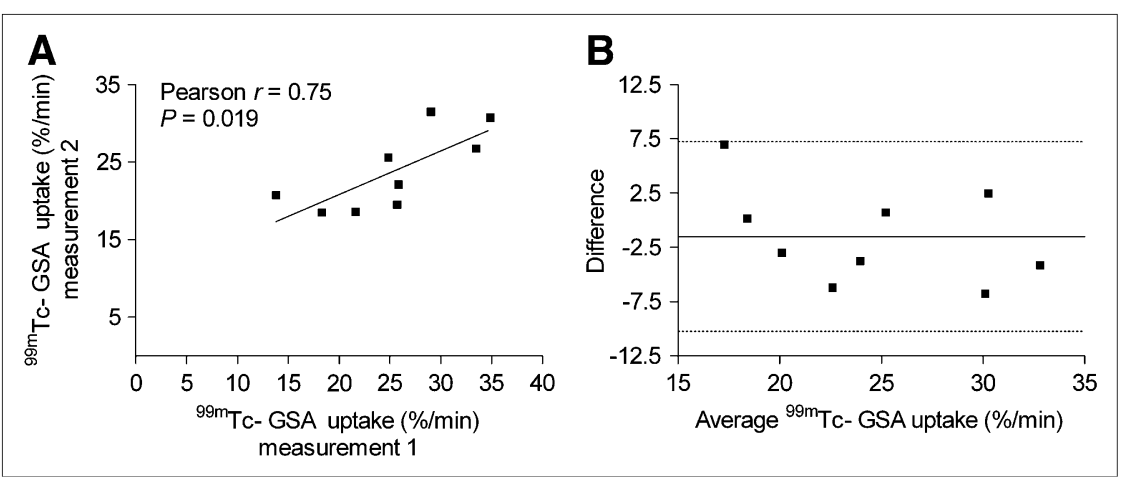

FIGURE 3. (A) Correlation between 2 measurements of $99 \mathrm{mTc}-\mathrm{GSA}$ uptake was significant and strong $(r=0.754, P=$ 0.019). (B) The Bland-Altman analysis shows a small bias between the 2 measurements (mean bias, $-1.49 \% / \mathrm{min}$ ), with the $95 \%$ limit of agreement between $-10.22 \% / \mathrm{min}$ and $7.24 \% / \mathrm{min}$. 
FIGURE 4. (A) Correlation between functional volume assessed by ${ }^{99 \mathrm{mTC}}$ GSA SPECT and conventional liver volume was strong and significant $(r=0.93$, $P<0.0001)$. (B) Correlation between 99mTc-GSA uptake and conventional liver volume was moderate $(r=0.62, P=$ 0.046).

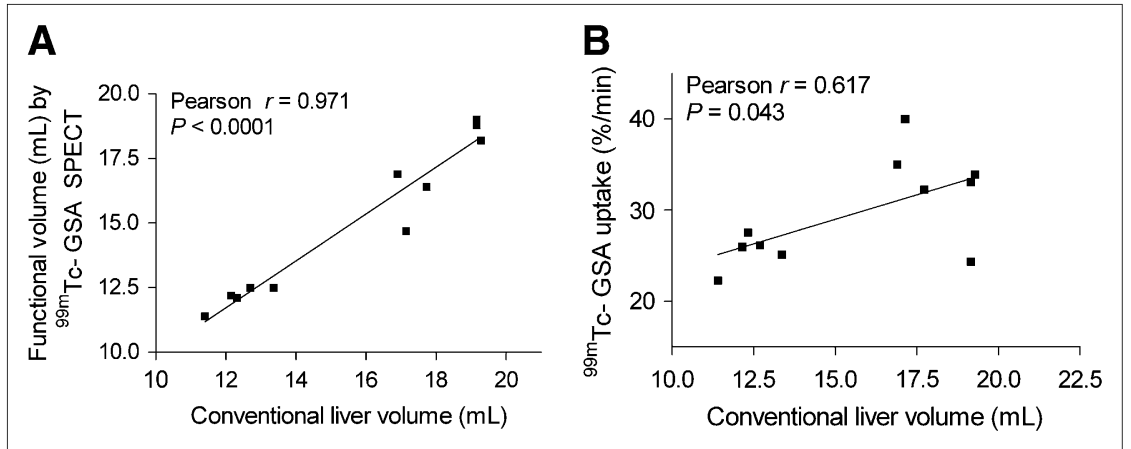

and $5 \mathrm{~d}$ after $70 \% \mathrm{PH}$, it decreased to $1.46 \% \pm 0.13 \% / \mathrm{min} /$ $\mathrm{g}$ and $1.32 \% \pm 0.10 \% / \mathrm{min} / \mathrm{g}$, respectively (vs. baseline, $P=0.008$ and $P=0.004$, respectively; Mann-Whitney test). At day 7, the ${ }^{99 \mathrm{~m}} \mathrm{Tc}-\mathrm{GSA}$ uptake per liver weight had returned to baseline level-that is, $2.18 \% \pm 0.13 \% / \mathrm{min} / \mathrm{g}$ (vs. baseline, $P=0.08$; Mann-Whitney test).

\section{Comparison Between 99mTc-GSA Uptake, Liver Functional Volume, and Liver Volume During Liver Regeneration}

To compare ${ }^{99 \mathrm{~m} T c-G S A}$ uptake, liver functional volume, and conventional liver volume during liver regeneration, data were expressed as a percentage of baseline measurements (Fig. 7). During the regeneration process, there were no significant differences between conventional liver volume and liver functional volume assessed by ${ }^{99 \mathrm{~m} T c-G S A}$ SPECT $(P=0.144$, nonparametric repeated measurement ANOVA). There were, however, significant differences between ${ }^{99 m}$ Tc-GSA uptake and liver volume $(P<$ $0.001)$ and liver functional volume $(P<0.001)$. When the separate time points were analyzed, significant differences between ${ }^{99 \mathrm{~m}} \mathrm{Tc}-\mathrm{GSA}$ uptake and liver volume were found at day $1(P<0.001)$, day $3(P=0.09)$, and day 5 $(P<0.001)$ after $70 \%$ PH. At day 7 , there were no significant differences $(P=0.14)$.

\section{DISCUSSION}

The liver has the unique ability to regenerate after a partial liver resection. In the clinical setting, liver regeneration is traditionally evaluated using CT volumetry. How- ever, during liver regeneration, hepatic volume does not always represent hepatocellular function (5-7). Consequently, additional functional assessment of the regenerating liver should be considered.

As liver regeneration is difficult to study in humans, a standardized rat model of $70 \% \mathrm{PH}$ is commonly used. Similar to the clinical situation, liver regeneration is generally assessed by increase of liver volume. Only a few studies have investigated the recovery of liver function after $\mathrm{PH}$. In this study we evaluated the utility of ${ }^{99 \mathrm{~m}} \mathrm{Tc}-\mathrm{GSA}$ scintigraphy combined with SPECT for the assessment of liver function and liver functional volume in normal and regenerating rat liver.

${ }^{99 \mathrm{~m}} \mathrm{Tc}-\mathrm{GSA}$ liver scintigraphy was developed in Japan as a noninvasive liver function test. The liver is the only uptake site for ${ }^{99 \mathrm{~m}} \mathrm{Tc}-\mathrm{GSA}$ and, therefore, it is an ideal agent for functional liver scintigraphy. It is assumed that the ligand-receptor binding is a second-order process, in which a significant fraction of receptor is occupied during the course of the imaging study. ${ }^{99 \mathrm{~m}} \mathrm{Tc}-\mathrm{GSA}$ remains trapped in the liver for at least $30 \mathrm{~min}$ (17). This enables SPECT acquisitions in small laboratory animals for the assessment of both liver function and liver functional volume.

Clinical studies report a correlation with conventional liver function tests, including antithrombin III, total and direct bilirubin, prothrombin time, indocyanine green clearance, Child-Pugh classification, and histology (hepatic activity index score) $(19,24)$. However, the broader use of 99mTc-GSA liver scintigraphy has been hampered by the fact that it has not been approved for clinical use in Europe

FIGURE 5. Liver functional volume and conventional liver volume were decreased the first day after $70 \% \mathrm{PH}$. (A) In the following time, liver regenerated to its normal volume at day 5 and day 7 after resection. (B) Correlation between liver volumes in regenerating liver assessed by conventional analysis and 99mTc-GSA SPECT was significant and strong (Pearson $r=0.924, P<0.0001$ ).

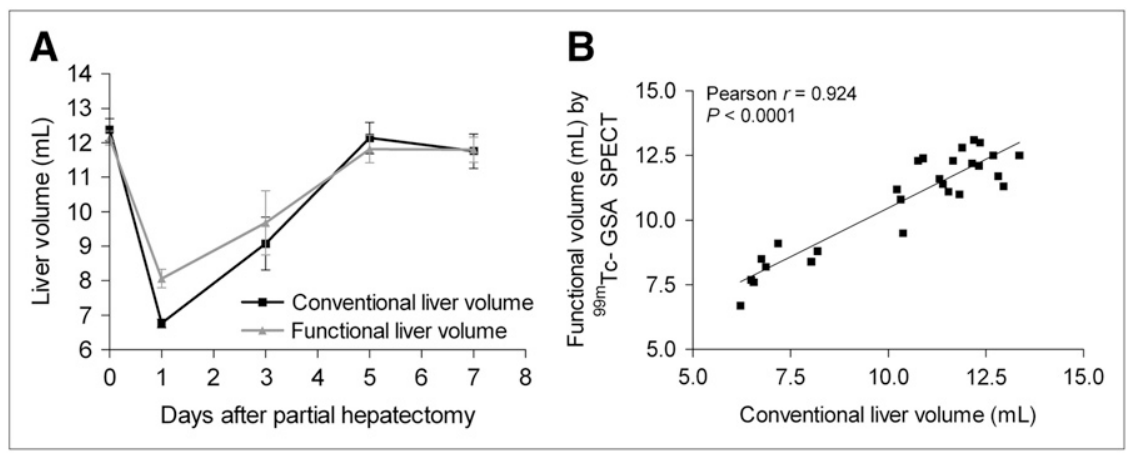




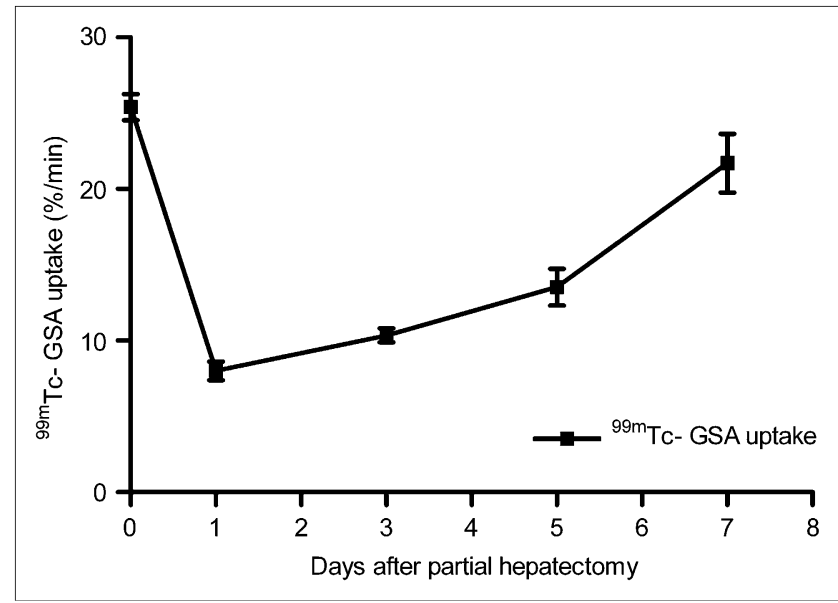

FIGURE 6. ${ }^{99 m}$ Tc-GSA uptake decreased the first day after $70 \% \mathrm{PH}$, after which it slowly recovered to baseline uptake at day 7 after resection.

and the United States. ${ }^{99 \mathrm{~m} T c-G S A}$ is available for preclinical investigation outside of Japan. In the clinical situation, liver function measured by ${ }^{99 \mathrm{~m} T c-G S A}$ scintigraphy, is expressed by many different, sometimes complex, parameters $(12,19,25-28)$. In our study, we applied a method that calculates the hepatic binding rate on the basis of liver ${ }^{99 \mathrm{~m} T c-G S A}$ uptake and the count ratio of liver to blood pool. ${ }^{99 \mathrm{~m} T c-G S A}$ SPECT was used for the calculation of liver functional volume, using the outline extraction method (29).

In the normal rat, as well as during the regeneration process of the liver, we demonstrated a strong correlation between conventional liver volume and liver functional volume Therefore, ${ }^{99 \mathrm{~m}} \mathrm{Tc}$-GSA SPECT is an accurate, non invasive method to assess liver functional volume in normal rat liver.

After $70 \% \mathrm{PH}$, a discrepancy between volumetric ( ${ }^{99 \mathrm{~m}} \mathrm{Tc}-\mathrm{GSA}$ SPECT, conventional analysis) and functional ( ${ }^{99}$ Tc-GSA uptake) recovery was observed during the regeneration process. ${ }^{99 \mathrm{~m}} \mathrm{Tc}-\mathrm{GSA}$ uptake underestimated hepatic regeneration in comparison with liver volume. In both clinical and experimental studies, a discrepancy has been described between volumetric regeneration and functional regeneration after $\mathrm{PH}$. Tanaka et al. reported that functional regeneration was impaired in large resections in comparison with volumetric regeneration (28). This can be explained by the theory that, during liver regeneration, hepatocyte proliferation is promoted at the expense of liver

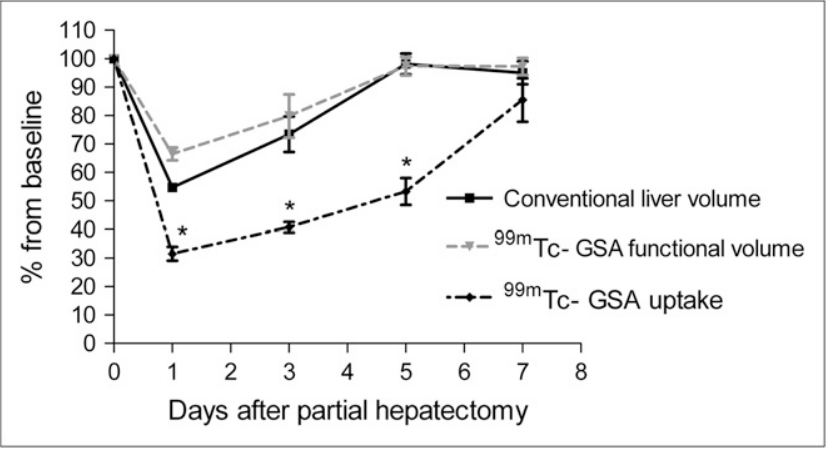

FIGURE 7. During the regeneration process, there were significant differences between 99mTc-GSA uptake and both conventional liver volume $(P<0.001)$, and liver functional volume $(P<0.001)$, when data were expressed as a percentage of baseline levels.

function (30). Others, however, concluded that the functional regeneration was more rapid than the morphologic regeneration $(6,7)$. These results support the theory that hepatocyte function is upregulated after major hepatic resection to compensate for the reduced liver mass $(22,31,32)$. Therefore, it remains difficult to draw conclusions with regard to the difference between functional and volumetric regeneration.

In our study, ${ }^{99 \mathrm{~m}} \mathrm{Tc}-\mathrm{GSA}$ uptake was decreased in the first days after partial liver resection, which was not only due to the decrease in liver weight after resection. The ${ }^{99 \mathrm{~m} T c-G S A}$ uptake per gram liver was significantly decreased during the first days after resection, which returned to baseline at day 7. Although the uptake of ${ }^{99 m} \mathrm{Tc}-G S A$ is influenced by blood flow, liver perfusion is increased after partial liver resection due to the fact that the complete portal flow is directed through the small remnant liver (33). When the remnant liver increases, portal perfusion returns to baseline levels. It has been suggested that increased liver perfusion after resection is one of the main triggers for regeneration (33). Therefore, it is unlikely that the decrease in ${ }^{99 \mathrm{~m}} \mathrm{Tc}-\mathrm{GSA}$ uptake, as found in this study, results from a change in liver perfusion because this is increased during the first days after liver resection.

The decrease in uptake per gram liver can be explained by a decrease in ASGP receptors per hepatocyte, a decrease in affinity of the ASGP receptor, or a decrease in the amount of hepatocytes per gram liver. In vitro studies have described a decrease in surface ASGP receptors during liver

TABLE 1

99mTc-GSA Uptake per Liver Weight in Regenerating Liver After 70\% $\mathrm{PH}$

\begin{tabular}{cccccc}
\hline Parameter & Baseline & Day 1 & Day 3 & Day 5 & Day 7 \\
\hline${ }^{99 m T c-G S A ~}(\% / \mathrm{min} / \mathrm{g})$ & $2.44 \pm 0.17$ & $1.51 \pm 0.08^{*}$ & $1.46 \pm 0.13^{*}$ & $1.32 \pm 0.10^{*}$ & $2.18 \pm 0.13$ \\
& & & & \\
\hline${ }^{*}$ Versus baseline, $P<0.05$; Mann-Whitney test. & & & \\
\hline
\end{tabular}


regeneration (34,35). Mechanisms of decreased cell-surface ASGP receptors include the secretion of the ASPG receptor into the extracellular space and reduced recycling of the receptor after endocytosis (34). Our results may support the theory that the amount of ASGP receptors is decreased, and it is uncertain whether dynamic ${ }^{99 \mathrm{~m} T c-G S A}$ scintigraphy still accurately represents liver function during the early phase of regeneration. Therefore, further validation and investigation of possible mechanisms of the decrease of ASGP receptor is advised before it can be used for the assessment of liver function in a regenerating rat liver.

\section{CONCLUSION}

${ }^{99 m}$ Tc-GSA scintigraphy combined with SPECT is a feasible, noninvasive method to assess hepatic volume in normal rat liver as well as in the regenerating rat liver. However, the hepatic ${ }^{99 \mathrm{~m}} \mathrm{Tc}-\mathrm{GSA}$ uptake seems to underestimate hepatic regeneration, possibly due to a decrease of ASGP receptors in the early phase after PH.

\section{ACKNOWLEDGMENTS}

The authors thank Michael Tanck (Department of Clinical Epidemiology and Biostatistics, Academic Medical Center) for his help with the statistical analysis.

\section{REFERENCES}

1. Llovet JM. Updated treatment approach to hepatocellular carcinoma. J Gastroenterol. 2005;40:225-235.

2. Vetelainen R, van Vliet AK, van Gulik TM. Severe steatosis increases hepatocellular injury and impairs liver regeneration in a rat model of partial hepatectomy. Ann Surg. 2007;245:44-50.

3. Yokoyama Y, Nagino M, Nimura Y. Mechanisms of hepatic regeneration following portal vein embolization and partial hepatectomy: a review. World $J$ Surg. 2007;31:367-374.

4. Palmes D, Spiegel HU. Animal models of liver regeneration. Biomaterials. 2004; 25:1601-1611.

5. Bennink RJ, Dinant S, Erdogan D, et al. Preoperative assessment of postoperative remnant liver function using hepatobiliary scintigraphy. J Nucl Med. 2004; 45:965-971.

6. Kwon AH, Matsui Y, Ha-Kawa SK, Kamiyama Y. Functional hepatic volume measured by technetium-99m-galactosyl-human serum albumin liver scintigraphy: comparison between hepatocyte volume and liver volume by computed tomography. Am J Gastroenterol. 2001;96:541-546.

7. Kwon AH, Matsui Y, Kaibori M, Kamiyama Y. Functional hepatic regeneration following hepatectomy using galactosyl-human serum albumin liver scintigraphy. Transplant Proc. 2004;36:2257-2260.

8. Daniel GB, DeNovo RC, Schultze AE, Schmidt D, Smith GT. Hepatic extraction efficiency of technetium-99m-mebrofenin in the dog with toxic-induced acute liver disease. J Nucl Med. 1998;39:1286-1292.

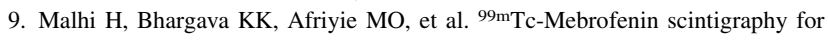
evaluating liver disease in a rat model of Wilson's disease. J Nucl Med. 2002; 43:246-252.

10. Bennink RJ, Vetelainen R, de Bruin K, van Vliet AK, van Gulik TM. Imaging of liver function with dedicated animal dynamic pinhole scintigraphy in rats. $\mathrm{Nucl}$ Med Commun. 2005;26:1005-1012.

11. Vetelainen RL, Bennink RJ, de Bruin K, van Vliet A, van Gulik TM. Hepatobiliary function assessed by ${ }^{99 \mathrm{~m}} \mathrm{Tc}$-mebrofenin cholescintigraphy in the evaluation of severity of steatosis in a rat model. Eur J Nucl Med Mol Imaging. 2006;33:1107-1114.

12. Kokudo N, Vera DR, Makuuchi M. Clinical application of TcGSA. Nucl Med Biol. 2003;30:845-849.

13. Akaki S, Mitsumori A, Kanazawa S, et al. Technetium-99m-DTPA-galactosyl human serum albumin liver scintigraphy evaluation of regional CT/MRI attenuation/signal intensity differences. J Nucl Med. 1998;39:529-532.

14. Marshall JS, Green AM, Pensky J, Williams S, Zinn A, Carlson DM. Measurement of circulating desialylated glycoproteins and correlation with hepatocellular damage. J Clin Invest. 1974;54:555-562.

15. Matsuzaki S, Onda M, Tajiri T, Kim DY. Hepatic lobar differences in progression of chronic liver disease: correlation of asialoglycoprotein scintigraphy and hepatic functional reserve. Hepatology. 1997;25:828-832.

16. Sawamura T, Kawasato S, Shiozaki Y, Sameshima Y, Nakada H, Tashiro Y. Decrease of a hepatic binding protein specific for asialoglycoproteins with accumulation of serum asialoglycoproteins in galactosamine-treated rats. Gastroenterology. 1981;81:527-533.

17. Kudo M, Washino K, Yamamichi Y, Ikekubo K. Synthesis and radiolabeling of galactosyl human serum albumin. Methods Enzymol. 1994;247:383-394.

18. Habraken JB, de Bruin K, Shehata M, et al. Evaluation of high-resolution pinhole SPECT using a small rotating animal. J Nucl Med. 2001;42:1863-1869.

19. Kwon AH, Ha-Kawa SK, Uetsuji S, Kamiyama Y, Tanaka Y. Use of technetium 99m diethylenetriamine-pentaacetic acid-galactosyl-human serum albumin liver scintigraphy in the evaluation of preoperative and postoperative hepatic functional reserve for hepatectomy. Surgery. 1995;117:429-434.

20. Ekman M, Fjalling M, Holmberg S, Person H. IODIDA clearance rate: a method for measuring hepatocyte uptake function. Transplant Proc. 1992;24:387-388.

21. Kudo M, Vera DR, Stadalnik RC. In vivo quantification of asialoglycoprotein receptor. Methods Enzymol. 1994;247:373-382.

22. Jansen PL, Chamuleau RA, van Leeuwen DJ, Schipper HG, Busemann-Sokole E, van der Heyde MN. Liver regeneration and restoration of liver function after partial hepatectomy in patients with liver tumors. Scand J Gastroenterol. 1990; 25:112-118.

23. Chan SC, Liu CL, Lo CM, et al. Estimating liver weight of adults by body weight and gender. World J Gastroenterol. 2006;12:2217-2222.

24. Sasaki N, Shiomi S, Iwata Y, et al. Clinical usefulness of scintigraphy with ${ }^{99 \mathrm{~m}} \mathrm{Tc}$-galactosyl-human serum albumin for prognosis of cirrhosis of the liver. J Nucl Med. 1999;40:1652-1656.

25. Vera DR, Stadalnik RC, Metz CE, Pimstone NR. Diagnostic performance of a receptor-binding radiopharmacokinetic model. J Nucl Med. 1996;37:160-164.

26. Ha-Kawa SK, Tanaka Y. A quantitative model of technetium-99m-DTPAgalactosyl-HSA for the assessment of hepatic blood flow and hepatic binding receptor. J Nucl Med. 1991;32:2233-2240.

27. Miki K, Kubota K, Kokudo N, Inoue Y, Bandai Y, Makuuchi M. Asialoglycoprotein receptor and hepatic blood flow using technetium-99m-DTPA-galactosyl human serum albumin. J Nucl Med. 1997;38:1798-1807.

28. Tanaka A, Shinohara H, Hatano E, et al. Perioperative changes in hepatic function as assessed by asialoglycoprotein receptor indices by technetium $99 \mathrm{~m}$ galactosyl human serum albumin. Hepatogastroenterology. 1999;46:369-375.

29. Mitsumori A, Nagaya I, Kimoto S, et al. Preoperative evaluation of hepatic functional reserve following hepatectomy by technetium-99m galactosyl human serum albumin liver scintigraphy and computed tomography. Eur J Nucl Med. 1998;25:1377-1382.

30. Jochum C, Beste M, Penndorf V, et al. Quantitative liver function tests in donors and recipients of living donor liver transplantation. Liver Transpl. 2006;12:544549.

31. Kobayashi T, Imamura H, Aoki T, Sugawara Y, Kokudo N, Makuuchi M. Morphological regeneration and hepatic functional mass after right hemihepatectomy. Dig Surg. 2006;23:44-50.

32. Yildirim SI, Poulsen HE. Quantitative liver functions after $70 \%$ hepatectomy. Eur J Clin Invest. 1981;11:469-472.

33. Sato Y, Koyama S, Tsukada K, Hatakeyama K. Acute portal hypertension reflecting shear stress as a trigger of liver regeneration following partial hepatectomy. Surg Today. 1997;27:518-526.

34. Hirose S, Ise H, Uchiyama M, Cho CS, Akaike T. Regulation of asialoglycoprotein receptor expression in the proliferative state of hepatocytes. Biochem Biophys Res Commun. 2001;287:675-681.

35. Howard DJ, Stockert RJ, Morell AG. Asialoglycoprotein receptors in hepatic regeneration. J Biol Chem. 1982;257:2856-2858. 